\title{
Volatility Modeling and its Impact on Risk premium in Emerging markets
}

\author{
P.S. Morawakage
}

\begin{abstract}
This study examines different volatility models to capture the stock market volatility in two emerging markets Indonesia and Sri Lanka. Further the relationship between volatility and risk premium in both markets are analyzed to test the risk return trade off in those markets. GARCH, EGARCH and TGARCH models are used to capture the volatility and GARCH-M model is used to analyze the risk return relationship. In both markets it is observed that volatility clustering, leverage effect and nonlinear effect are significant by considering daily ASPI return observations from 2004 to 2013. Relationship between volatility and risk premium is not significant according to the GARCH-M model.
\end{abstract}

Key Words: Volatility, Risk Premium, GARCH, EGARCH, TGARCH, GARCH-M, Nonlinear, Leverage

\section{Introduction}

Stock market volatility has become a focal point of many researches since volatility itself a puzzle. Different markets shows different volatilities as high volatile markets and low volatile markets. Emerging markets are considered to be more volatile than developed markets. This volatility will determine the investors risk and return also. Therefore this study focus on stock market volatility and return behavior in Sri Lanka and Indonesia emerging markets. Here different econometric models will be discussed to capture correctly the volatility of those emerging markets and to understand the return behavior of such markets.

\section{Background Study}

It is likely that many relationships in finance are intrinsically non-linear. As Campbell, Lo and MacKinlay (1997) state, the payoffs to options are non-linear in some of the input variables, and investors' willingness to trade off returns and risks are also non-linear (Brook, 2008). These observations provide clear motivations for consideration of non-linear models in a variety of circumstances in order to capture better the relevant features of the risk return relationship.

Prabath Suranga Morawakage

Department of Finance, University of Kelaniya, Sri Lanka
Capital asset pricing model which is commonly used in finance explains a liner relationship between risk and return. However there is a problem how far it is reflected in current return series due to the fact that willingness to trade off returns and risks are also non-linear. Mehera \& Prescott (1985) and Elton (1999) have found that investors are not getting a return as they expected.

When there is high volatility there is a high risk. However investors still invest in volatile markets. Therefore it is important to analyze the volatility and return relationship is positive to compensate for the volatility. If the persistence of volatility shocks is long-term, then investors will require a risk premium in their required rate of return (Michelfelder \& Pandya, 2005)

Portfolio theory also play a vital role in explaining risk and return. Investors diversify away their risk by investing in different assets classes and markets. They can have stocks in high volatile markets to gain high returns and at the same time they can hold investments in low volatile markets to gain average returns at a low risk. Finally the portfolio risk is lower and they can gain a moderate return. The volatility is higher in emerging stock exchanges compared to matured markets (Michelfelder \& Pandya, 2005). However the problem is to which degree of risk an investor is exposed in an emerging volatile market and how much he is paid off to the corresponding risk. Can he just construct a portfolio blindly without proper understanding of the volatility of the emerging markets?

Volatility of emerging markets is not easily captured by annualized standard deviation of equity index. And again volatility and returns are nonlinear as explained earlier. Linear structural (and time series) models such as linear regression, Auto Regressive Moving Average (ARMA) are also unable to explain a number of important features common to stock returns over a period of time. Such important features include Leptokurtosis, Volatility clustering or volatility pooling, Leverage effects (Brook, 2008).

Therefore there are various models to capture those characteristics and Autoregressive Conditional Heteroskedasticity $(\mathrm{ARCH})$ type models are very popular among them.

This background suggests that volatility is a significant factor in determining the expected return and make a subsequent effects on the asset pricing. Therefore to understanding the volatility in emerging markets and emphasizing its implications on different finance theories 
has become a significant contribution in recent papers in this area.

Therefore studying "how to explain the volatility and its impact on stock returns in emerging markets" will be important. This problem statement can be further investigated through the research questions given below.

\section{A. Research Questions}

- How volatility behave in emerging markets?

- Which model more appropriate to explain the volatility in emerging markets?

- How volatility affects return in selected markets?

Literature suggests that there is a high volatility in emerging markets. This nature will be investigated with appropriate techniques and models. Many time series data contain heteroskedasticity problem, where the variances of the error terms are not equal, and in which the error terms may be expected to be larger for some observations or periods of the data than for others. This behavior makes it difficult to understand the risk return behavior of a given asset class and make inferences on that. The issue is then how to construct models that accommodate heteroskedasticity so that valid coefficient estimates and models are obtained for the variance of the error terms for better decision making.

\section{B. Objectives of the study}

In order to address the research questions followings objectives are formulated.

\section{Objective 01}

To examine the volatility in the areas of clustering,leverage effects and sudden shocks in emerging markets

\section{Objective 02}

To Compare and contrast, GARCH, EGARCH and TGARCH models in explaining volatility in emerging markets

\section{Objective 03}

To analyze the return behavior of emerging markets

\section{Significance of the Study}

Different researchers have used different models and techniques to understand the volatility puzzle in different markets. They have highlighted pros and cons of each. This research also will try to understand the appropriateness of different models in explaining the volatility and return behavior of emerging markets.

Predicting volatility helps investors to make abnormal returns. This research focus on volatility prediction models and their validity.in a given context. For high-frequency data the time horizon of observations is very short. In this context, this research will discuss the daily data as opposed to monthly or quarterly data. Large price variations occur more and more frequently in stock markets so that the modelling of daily price movements and volatilities becomes an important task for active traders and market makers. As liquid assets are traded many times during a given period, there is potentially useful information in the daily prices about the variance.

\section{Literature Review}

Volatility is up-and-down movement of the market. There are wide ranging compromises on what comprises stock market volatility and, on how to measure it. (Peiris \& Peiris, 2012). According to Schwert (1990) it is measured by standard deviation from the expectation. However Fayyad \& Daly, 2010 explain conditional volatility as a better measurement.

Investments in emerging markets are increasing and popular. Emerging markets display few anomalies and there is evidence of return predictability. (Claessen, Dasgupt, \& Glen , 1995). At the same time, it is well known that emerging stock markets are characterized by high volatility (Bekaert \& Harvey, 1997; Aggarwal, Inclan, \& Leal, 1999; Michelfelder \& Pandya, 2005). The sample variances and the standard deviations of all the series clearly show that the volatility of the Japan and U.S. stock exchanges are comparatively lower than the volatility of the other emerging exchanges (Michelfelder \& Pandya, 2005). Bekaert \& Harvey (1997) have found that Colombia, Indonesia and Korea countries have volatility greater than $30 \%$ and both the range and the magnitude of the volatilities is much greater than found in developed markets.

Further, mature markets follow a random walk suggesting markets are efficient in the weak-form, and the emerging markets are not due to the predictability of emerging market returns using past returns (Michelfelder \& Pandya, 2005).

Though many researchers argue that emerging markets are more volatile than developed markets no proper explanation has been given why is it happening so. As Schwert (1990) mention that it is unclear whether the large volume of trading causes high volatility, or whether the high volatility and trading volume both reflect the arrival of important information. Then how investors react for negative information and positive information. Then negative information may have a different impact than a positive impact. This has been explained by Glosten, Jagannathan, \& Runkle, 1993; Zakoian, 1991 by introducing GJR model and TGARCH model respectively. According to their explanation risk and return is having a nonlinear relationship since negative shock create more volatility than a positive shock. Further Black in 1971 found there is a leverage impact in the equity return series suggesting a negative return would create more volatility than a positive return with the same magnitude.

Then how such volatility changes can be incorporated into scientific modeling. Therefore, asset market return 
volatility prediction is at the top of the finance literature. Time series modeling is very popular in this context. Modified time series analysis such as Autoregressive Conditional Hetroskedasticity (ARCH) proposed by Robert F Engle, 1982, Generalized ARCH (GARCH) Tim Bollerslev, 1986 and Exponential GARCH (EGARCH) proposed by Nelson, 1991 are heavily used.

Alberg, Shalit, \& Yosef (2008) suport the view that both the ARCH and GARCH models capture volatility clustering and leptokurtosis in high volatile markets, but as their distribution is symmetric, they fail to model the leverage effect which is one of prominent charachteristic of volatlity.

However many studies have found out that EGARCH is able to describe adequately the return process of the emerging markets under volatility. However Michelfelder \& Pandya (2005) has explained EGARCH specification better fits the mature market returns than the emerging market returns. This scenario raises some controversy since as explained earlier emerging markets are more volatile than developed markets so that how a common model explain two different scenarios.

Fung and Poon (2000) found that EGARCH-M model was a much better candidate for Chinese securities. EGARCH-M also an asymmetric GARCH model suggesting asymmetric GARCH models are more appropriate to explain the emerging markets' equity indices.

Lim \& Sek (2013) has done a study on Malayasia Stock market to capture the volatility using symmetric and assymetric GARCH (EGARCH and TGARCH) with a pre crisis and post crisis analysis. for the normal period (pre and post-crisis), symmetric GARCH model perform better than the asymmetric GARCH but for fluctuation period (crisis period), asymmetric GARCH model is preferred (Lim \& Sek, 2013).

In Sri Lanka there are few studies on stock market volatility.Study of Jaleel \& Samarakoon (2009) examines the impact of liberalization of the Sri Lankan stock market on return volatility. They specify GARCH and TGARCH models of volatility. The results show that liberalization of the market to foreign investors significantly increased the return volatility in the Colombo Stock Exchange and the market is more volatile to positive shocks than negative shocks indicating that no leverage effect exists in the market. (Jaleel \& Samarakoon, 2009) .

Therefore another confustion is the finding of Jegajeevan (2010) . According to him, asymmetric EGARCH model has found the presence of asymmetric volatility indicating that the market reacts more to a negative than shock a positive shock of the same size (Jegajeevan, 2010). Same market two different researchers find that Leverage effect is not present. However Jaleel and Samarakoon (2009) has studied weekly returns whereas Jegajeevan (2010) has studied daily returns.
Kumara, Upananda, \& Rajib, 2014 has done a study on dynamic properties of Colombo Stock Exchange under pre war and post war condition. The have also emplyed TGARCH and EGARCH to capture the nonlinear aspect of volatility. Further they have employed GARCH-M approach to analyze the risk return relationship in the market.

Further, Bekaert \& Harvey, (1997) emphasised the choice of model was difficult for Indonesia. They explain asymmetric GARCH provides an improvement in fit for most of the countries except for Indonesia, Jordan, Nigeria, Taiwan and Turkey

Most of the market's highest returns occurred during the Great Depression, from 1929 to 1939. Several patterns has been identified in the research of Schwert, 1990. First, there are many reversals, large drops in stock prices being followed by large increases. This scenario helps investors to make abnormal returns by following the patterns.

Moreover, there are conflicting empirical findings on volatility and return. For example, French, Schwert, and Stambaugh (1987) and Campbell and Hentschel (1992) Bollerslev Engle, and Wooldrige (1988), Turner, Startz, and Nelson (1989), Harvey (1989), Scruggs (1998), and Veronesi (1999) find the relation between volatility and expected return to be positive. Kim, Morley, \& Nelson, 2004 also find that there is a significant positive relationship between stock market volatility and the equity premium.

Turner, Startz, and Nelson (1989), Glosten, Jagannathan, and Runkle (1993), and Nelson (1991) find the relation to be negative which is contradictory to the above findings. A drop in the value of the stock (negative return) increases financial leverage, which makes the stock riskier and increases its volatility (Wu G. , 2001)

Volatility is very important issue for studying the behavior of stock markets. Investors are interested in modeling volatility behavior to predict the stock returns. Investors prefer emerging markets over mature markets since they expect higher returns from the emerging markets. This research is important to study the volatility of the emerging markets with various models and thereby to draw some inferences on return behavior of emerging markets.

\section{Methodology}

\section{A. Conceptual Framework and Operationalization}

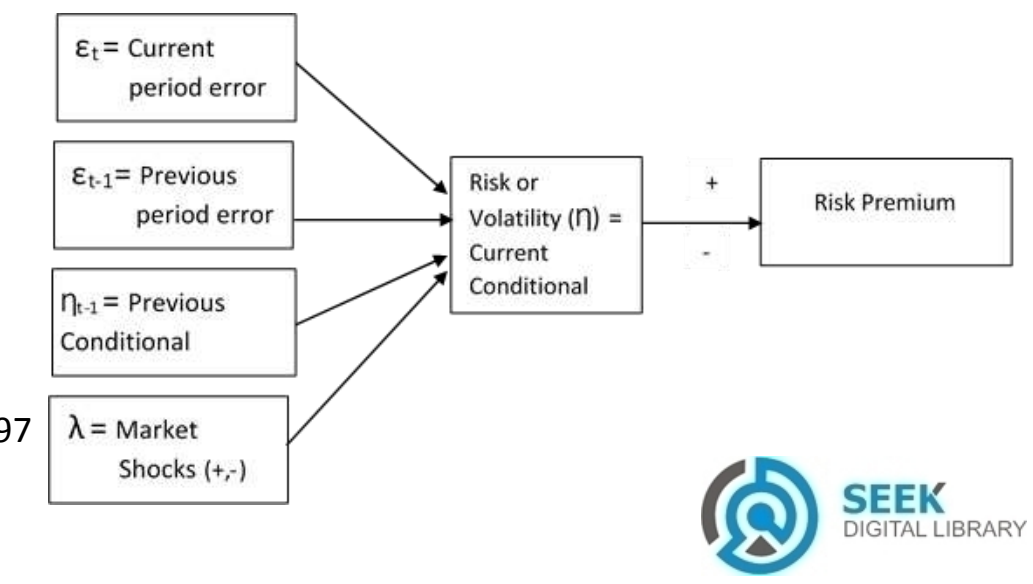


Variance is the measurement of Volatility. However, literature and many econometric books suggest that if there is volatility clustering Conditional variance is the most suitable measurement of the volatility. According to the background study it was observed that there are volatility clustering in both markets under study and hence conditional variance will be a determinant of volatility as given in the above figure. Volatility is the proxy for risk of different markets which is the independent variable. However independent variables such as current and previous error terms, previous conditional variance and leverage effect in the return distribution will make an impact on the volatility.

The dependent variable is the risk premium of a given market. Here risk premium is the excess return generated by a market between two consecutive time periods as explained by Backus \& Gregory, 1993.

Initially mean equation will be defined base on the simple linear regression of Auto Regressive (AR) models. Significant model will be taken to determine the number of AR terms.

ARCH-M model can be developed with different GARCH (p,q) models or EGARCH (p,q) models based on the nature of the time series data under consideration. Further financial time series data contain excess kurtosis and skewedness.

Therefore assuming normal distributions for estimations may not be suitable. Then Generalized Error Distributions (GED) or Student t distribution will be used to estimate the parameters of ARCH models. Akaike and Schwarz information criteria will be used to select the best model appropriately.

\section{B. ARCH Model specification}

$\mu_{\mathrm{i}, \mathrm{t}}=\beta_{0}+\mu_{\mathrm{it}-1}+\beta_{1} \eta_{\mathrm{it}} \quad$ - Mean Equation

$\eta_{\mathrm{it}}=\alpha_{0}+\alpha_{1} \varepsilon_{t-1}^{2} \ldots \ldots .+\alpha_{\mathrm{q}} \varepsilon_{t-q}^{2} \quad$ - Variance Equation

$\mu_{\mathrm{i}, \mathrm{t}}=$ Equity Return of $\mathrm{i}$ market at time $\mathrm{t}$

$\eta_{\text {it }}=$ Conditional variance of daily returns of market at time $t$

$\beta_{0}, \alpha_{0}=$ Constant parameter

$\alpha_{1}=$ Slope parameter of Squared error of daily returns in i market at time t-1

$\beta_{1}=$ Slope parameter of Conditional variance of daily returns of i market at time $\mathrm{t}$

$\varepsilon_{t-1}^{2}=$ Squared error of daily returns in i market at time t-1

$\eta_{\mathrm{it}-\mathrm{1}}=$ Conditional variance of returns in i market at time $\mathrm{t}-1$

Another advance model is Generalized Autoregressive Conditionally Heteroscedastic (GARCH) model where previous immediate or latter conditional variances are also taken into account when the current conditional variance is determined. This also can be developed to GARCH $(1,1)$ and so on. GARCH process is not a usual linear model since conditional variance has an impact. Therefore estimation is not taken place with the Ordinary Least Square (OLS) method and instead of that Maximum Likely hood method is used. Further EGARCH model can be used to capture the leverage impact and TGARCH model can be used to analyze the impact of negative innovations on the volatility.

With the above models researcher would be able to know which factors drive the volatility in the selected markets. Whether volatility is driven by immediate shocks, conditional variance, leverage effect or negative shocks.

\section{ARCH-M model of Risk Premiums}

Finance theory holds that investors should be rewarded for taking risks. The $\mathrm{ARCH}$ in mean (ARCH-M) model provides a comprehensive link between the risk (conditional volatility) and the best forecast of a return time series. Work of Backus \& Gregory, 1993 under the Theoritical Relations between Risk Premium and Conditional Variances is used to develop ARCH- M model here. Using Auto Regressive (AR) modal is not sensible here to talk about risk return relation ship since return $\left(\mathrm{Y}_{\mathrm{t}}\right)$ is a function of the lags of the same return as

$$
\mu_{\mathrm{t}}=\mathrm{E}\left(Y_{t} \mid I_{t-1}\right)=\alpha \mathrm{y}_{\mathrm{t}-1}+\varepsilon_{\mathrm{t}}
$$

Here $\mu_{t}$ is the better forecast of $Y_{t}$ (Return at time t). $\mathbf{I}_{t-1}$ is the information set available at time $\mathrm{t}-1$. Therefore return is not propotional to the risk. However,Residuals $\left(\varepsilon_{t}\right)$ are distributed as $\varepsilon_{\mathrm{t}} \mathrm{I}_{\mathrm{t}-1} \sim \mathrm{N}\left(0, \eta_{\mathrm{t}}^{2}\right)$ where

$$
\eta_{t}^{2}=\omega+\sum_{i=1}^{q} \alpha \varepsilon_{t-i}^{2}
$$

As a solution ARCH-M modal can be incorporated as follows.

$$
\mathrm{Y}_{\mathrm{t}}=\mathrm{c}+\delta \eta_{\mathrm{t}}+\varepsilon_{\mathrm{t}}
$$

where $\varepsilon_{\mathrm{t}}$ is $\operatorname{ARCH}(\mathrm{q})$ with $\left\{\varepsilon_{t} \mid I_{t-1}\right\} \sim \mathrm{N}\left(0, \eta_{\mathrm{t}}^{2}\right)$. Then the best forecast of $Y_{t}$ given $I_{t-1}$ is the conditional mean.

$$
\mu_{\mathrm{t}}=\mathrm{E}\left(Y_{t} \mid I_{t-1}\right)=\mathrm{c}+\delta \eta_{\mathrm{t}}
$$

Here unlike autoregressive models risk is explicitly captured by conditional standard deviation $\left(\eta_{t}\right)$. The above formula implies that the conditional mean $\left(\mu_{\mathrm{t}}\right)$ is proportional to the risk (Conditional standard deviation, $\eta_{\mathrm{t}}$ ). It explains when the risk of a return series increases or decreases return also changes proportionately. This scenario helps us to achieve the first objective of understanding the requirement of a risk premium to compansate the risk changes.

$$
r_{t+1}=\mu_{t}+\varepsilon_{t+1}
$$

As Backus \& Gregory, 1993 explain $E_{t}$ is the expectation operator conditional on the date-t information set, $\mu_{t}=E_{t} r_{t+1}$ and $\varepsilon_{t+1}=r_{t+1}-E_{t} r_{t+1}$. If $r_{t+1}$ is excess 
return then the conditional mean, $\mu_{t}$, is generally referred to as risk premium.

Therefore ARCH-M type models will help to understand whether the risk premium for volatility is positive, negative or not significant.

\section{Data gathering}

Appropriate data gathering technique is secondary and quantitative. Realized daily returns from 2004 to 2013 for each market will be collected. Bloomberg Data base will be used to gather the data from Indonesia and Sri Lanka which are emerging stocks markets. These are time series data for two equity markets separately. Using the ASPI figures of both markets return series will be obtained.

\section{E. Hypothesis testing for objectives}

Following models will be used to achieve the first objective

\section{GARCH (1,1) Model}

Here we assume the current level of volatility tends to be positively correlated with its level during the immediately preceding periods (Brook, 2008). The GARCH model allows the conditional variance to be dependent upon previous own lags, so that the conditional variance equation in the simplest case is now

\section{Variance Equation}

$\eta_{\mathrm{t}}=\alpha_{0}+\alpha_{\mathrm{q}} \varepsilon_{t-q}^{2}+\phi_{\mathrm{p}} \eta_{\mathrm{t}-\mathrm{p}}$

If $\alpha_{\mathrm{q}}$ is significant there is an impact from previous shocks on the conditional variance. As well as if $\emptyset_{\mathrm{p}}$ is significant there is an impact from the previous conditional variance on the contemporaneous conditional variance. That means there is volatility clustering effect in the selected markets. $t$ statistics and $\mathrm{p}$ value will be used to test the hypothesis under 5\% significant levels.

Then the hypothesis will be

$$
\mathrm{H}_{0}: \emptyset_{\mathrm{p}} \leq{ }_{0}
$$$$
\mathrm{H} 1: \varnothing \mathrm{p}>0
$$

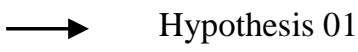

If $\emptyset_{p}$ is greater than zero, it indicates that there is a clustering effect since it is a positive relationship. Therefore $\mathrm{H}_{0}$ should be rejected and $\mathrm{H}_{1}$ should be accepted at $5 \%$ significant level.

Leverage effect will be captured through the EGARCH$M$ model and nonlinear impact will be captured through TGARCH- M model as follows.

\section{EGARCH model specification}

$$
\ln \eta_{\mathrm{t}}=\omega_{0}+\omega_{1} \ln \eta_{t-1}++\lambda \frac{\varepsilon_{t-1}}{\sqrt{\eta_{t-1}}}+\omega_{2}\left[\frac{\left|\varepsilon_{t-1}\right|}{\sqrt{\eta_{t-1}}}-\sqrt{\frac{2}{\pi}}\right]
$$

If $\lambda$ parameter is negative and significant it is said that leverage effect exist where a negative return would create

more volatility than a positive return with the same magnitude (Black 1971).

Therefore following Hypothesis will be tested.

$$
\begin{aligned}
& \mathrm{H}_{0}: \lambda \geq 0 \\
& \mathrm{H}_{1} \cdot \lambda<0
\end{aligned} \longrightarrow \text { Hypothesis } 02
$$

\section{TGARCH or GJR Model specification}

$$
\begin{aligned}
& \eta_{\mathrm{t}}=\alpha_{0}+\alpha_{1} \varepsilon_{t-1}^{2}+\phi_{1} \eta_{i t-1}+\gamma \varepsilon_{t-1}^{2} I_{t-1} \\
& \text { Where } I_{t-1}=1 \text { if } \varepsilon_{t-1}<0 \&=0 \text { otherwise }
\end{aligned}
$$

Slope parameter $\gamma$ should be positive and significant then if there are negative shocks $\left(\varepsilon_{t-1}<0, I_{t-1}=1\right)$ there is a more positive impact on the conditional variance other than a positive shock $\left(\varepsilon_{t-1}>0, I_{t-1}=0\right)$ (Zakoian, $1991 \&$ Glosten, et al., 1993). Then nonlinear impact can be observed in the data set. Therefore following Hypothesis will be tested.

$$
\begin{aligned}
& \mathrm{H}_{0}: \gamma \leq 0 \\
& \mathrm{H} 1: \gamma>0
\end{aligned} \longrightarrow \text { Hypothesis } 03
$$

\section{GARCH- M model}

$\mu_{\mathrm{it}}=\mathrm{E}\left(Y_{t} \mid I_{t-1}\right)=\mathrm{c}+\delta \eta_{\mathrm{t}}+\mathrm{Y}_{\mathrm{it}-1}$

Where

$\mu_{\mathrm{it}}=$ Expected return of $\mathrm{i}$ market at time $\mathrm{t}$

$\delta=$ Slope parameter of conditional variance at time $\mathrm{t}$ (Contemporaneous)

$\eta_{\mathrm{t}}=$ Conditional variance at time $\mathrm{t}$ (Contemporaneous)

$\mathrm{Y}_{\mathrm{it}-1}=$ Return of $\mathrm{i}$ market at time $\mathrm{t}-1$

If $\delta$ is positive and statistically significant, then increased risk, given by an increase in the conditional variance, leads to a rise in the mean return. Thus $\delta$ can be interpreted as a risk premium.

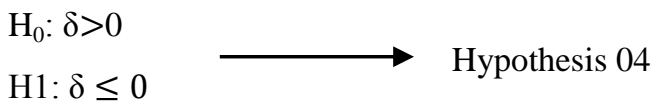

If null hypothesis is rejected there is a risk premium which is positive to compensate for the volatility of the market. If null is accepted there are no evidences to say that risk premium is present to compensate the volatility of the market. $t$ statistics and $p$ value will be used to test the hypothesis under 5\% significant levels.

\section{Analysis and discussion}

The number of observation was 2410 for both of these markets. The mean daily return was $0.076 \%$ and $0.086 \%$ for Sri Lanka market and Indonesia market respectively. The sample variances and the standard deviations of return distributions clearly show that the volatility of the Indonesia $(2.25 \%, 1.5 \%)$, is comparatively higher than the volatility of Sri Lanka $(1.21 \%, 1.1 \%)$ stock market return .There are indications of negative skewness ( -0.541 and -0.497$)$ in 
both of the markets which indicates that the lower tail of the distribution was thicker than the upper tail, that is, the indices decline occur more often than its increases. The kurtosis coefficients were positive, having high value for the return series (Kurt $=14.54$ and 8.90 ) that is the pointer of leptokurtosis or fat taildness in the underlying distributions.

Indonesia and Sri Lanka Stock market return series exhibit negative skewedness and excess kurtosis. The Jarque -Bera test rejects the normality hypothesis for every markets' returns probability distribution function (pdf)s as test statistic is larger and $\mathrm{p}$ value is close to zero.. The computed Jarque-Bera statistic value of 13488 and 3596 with P-values of zero rejected the normality assumption due to the high kurtosis also confirm the non-normality of the returns series. Stock and stock market return pdf's are highly skewed and leptokurtic. Therefore a flexible parameter pdf is required that can accommodate varying levels of skewness and kurtosis that typically characterize stock return pdf's (Michelfelder \& Pandya, 2005). Theodossiou, 1998 suggested if it is the case we can assume Skewed Generalized T Distribution for the data processing. Further Baillie \& DeGennaro, 1990 has suggested a conditional student $\mathrm{T}$ Distribution. They have mentioned Bollerslev (1987) and Baillie \& Bollerslev (1989) have provided example for the $t$ distribution approach. Therefore This investigation uses the Generalized Error Distribution (GED) and student $t$ distribution to deal with the anomalies in the financial data seris.

Liu et al. (2009), Alberga et al. (2008), and Hien (2008) have found that volatility forecasts by the GARCH-SGED model are more accurate than those generated using the GARCH-N model, indicating the significance of both skewedness and tail-thickness in the conditional distribution of returns (Lim \& Sek, 2013).

\section{A. Stationerity test}

Augmented Dickey-Fuller Test statistics for both markets are significant at $1 \%$ level suggesting there is not a unit root in both of the markets. Therefore both return series can be processed and tested for ARCH effect.

\section{B. ARCH Effect}

ARCH-LM test was carried out and statistically significant which indicates the presence of ARCH effect in the residuals of mean equation of both Indonesia ASPI index and Sri Lanka ASPI index. Then ARCH type models can be estimated to analyze the volatility and its impact on equity premium in the selected markets.

\section{Volatility Clustering}

GARCH 1, 1 model capture the volatility clustering of both markets. It is observed that conditional volatility parameter $\emptyset_{1}$ is significant and positive at $1 \%$ level at both markets suggesting volatility clustering effect assuming both pdf.

\section{Asymmetric and nonlinear volatility in emerging markets}

If the corresponding $p$ value of $\lambda$ is small and coefficient is negative, leverage effect is present as discussed under methodology. In Indonesian Market, it is highly significant at $1 \%$ level and negative suggesting there is a leverage effect under both $t$ and GED distributions. If leverage effect is present there is an asymmetric impact on volatility. That means there is a negative correlation between the past return and the future volatility of return where a positive shock has a less effect on the conditional variance compared to a negative shock. If return is lower (negative) higher the volatility and if return is high (positive) lower the volatility.

In Sri Lankan Market also, $\lambda$ is significant at $5 \%$ level and negative suggesting there is a leverage effect under both distributions.

TGARCH parameters are positive and significant at $1 \%$ level for both markets suggesting negative innovations have more impact than positive innovations.

\section{E. Discussion}

Volatility models assuming normal pdf is also not accepted as explained by Hansen, McDonald and Theodossiou, 2003 due to the leptokurtosis and skewedness in return distributions. Therefore this study carried out by assuming GED and student $t$ distributions instead of normal distributions.

Many emerging markets displays the volatility clustering (Kumara, et al., 2014; Michelfelder \& Pandya, (2005). This study also comply with many scholars finding as these two markets display the volatility clustering. However there are contradictory findings on asymmetric and no linear volatility.

Jaleel \& Samarakoon, 2009 have found that Sri Lanka market is more volatile to positive shocks than negative shocks indicating that no leverage effect exists in the market. At the same time Jegajeevan,2010 argue Asymmetric EGARCH model has found the presence of asymmetric volatility indicating that the market reacts more to a negative shock than a positive shock of the same size. Complying with Jegajeevan, 2010 this study also provide evidence of leverage effect in Sri Lanka Market. Indonesia market also displays leverage impact. Further both markets are significantly affected by the negative innovations than positive innovation as per TGARCH parameters.

EGARCH model is the best model to predict and analyze the volatility in Indonesia market whilst TGARCH model is the best for the Sri Lanka market according to the Akaike and Schw information criteria among GARCH, EGARCH and TGARH). Many researchers (Michelfelder \& Pandya, 2005; Bekaert \& Harvey, 1997) have rejected GAARCH as a better model to explain the volatility in emerging markets. However EGARCH has been accepted as a better model to describe the volatility in emerging markets (Michelfelder \& Pandya, 2005; Fung \& Poon, 2000; Lim \& Sek, 2013). 
TGARCH also has been accepted by some researchers (Wu, 2010; Jaleel \& Samarakoon, 2009; Kumara, et al., 2014).

It is important to discuss the relationship between volatility and the return or risk premium for the volatility. There are conflicting empirical findings. For example, French, Schwert, and Stambaugh (1987) and Campbell and Hentschel (1992), Bollerslev Engle, and Wooldrige (1988), Turner, Startz, and Nelson (1989), Harvey (1989), Scruggs (1998), and Veronesi (1999) find the relation between volatility and expected return to be positive while Turner, Startz, and Nelson (1989), Glosten, Jagannathan, and Runkle (1993), Nelson (1991), Bekaert \& Wu (2000), (Kim, Morley, \& Nelson (2004), Cox and Ross (1976) find the relation to be negative.

However volatility of the Indonesian ASPI return is positively related but not significant which is consistent with some researchers' findings (Kumara, Upananda, \& Rajib, 2014) regarding emerging markets as well as developed markets. That means there is no significant influence from the volatility to the conditional mean.

Volatility of the Sri Lanka ASPI return is also not significantly related with the return series though the relationship is positive. This finding is consistent with the Indonesian market which is an emerging markets.

\section{Conclusion}

Sri Lanka and Indonesia were taken as the emerging markets for the study. As discussed under literature, this study also evidences that emerging markets are highly volatile and characterized by volatility clustering, leptokurtosis, leverage effect and nonlinear impacts. Indonesian market is more volatile than Sri Lanka market. Even though those markets are volatile the impact on return is not significant but positive. Since both distributions are not significant it can be concluded that there no relationship between volatility and the risk premium in Sri Lanka as well as Indonesia stock market.

Further research may investigate the reason behind why emerging markets do not compensate for the risk significantly. This may have a significant contribution on asset pricing theories for emerging markets.

\section{VIII.References}

Wang, D. C., \& Mykland, P. A. (2012). The Estimation of Leverage effect with High Frequency Data. Journal of the American Statistical Association.

Aggarwal, R., Inclan, C., \& Leal, R. (1999). Volatility in Emerging Stock Markets. The Journal of Financial and Quantitative Analysis, 33-55.

Alberg, D., Shalit, H., \& Yosef, R. (2008). Estimating stock market volatility using asymmetric GARCH models. Applied Financial Economics, 1201-1208.

Backus, D. K., \& Gregory , A. W. (1993). Theoritical Relations between risk premium and conditional variances.
Journal of Business and Economic Statistics, Vol.11,No.2, 177-185.

Baillie, R. T., \& DeGennaro, R. P. (1990). Stock Returns and Volatility . The Journal of Financial and Quantitative Analysis, Vol. 25, 203-214.

Bekaert, G., \& Harvey, C. R. (1997). Emerging Equity Market Volatility. Journal of Financial Economics, 29-77.

Bekaert, G., \& Wu, G. (2000). Asymmetric Volatility and Risk in Equity Markets. The Review of Financial Studies, Vol. 13, 01-42.

Bollerslev, T. (1987). A Conditionally Hetroskedastic Time Series Model for Speculative Prices and Rates of Return. The Review of Economics and Statistics , 542-546.

Brook, C. (2008). Introductory Econometrics for Finance. Cambridge : Cambridge University Press.

Claessen, S., Dasgupt, S., \& Glen , J. (1995). Return Behavior in Emerging Stock Markets . The World Bank Economic Review, Oxford Journals , 131-151.

Claessen, S., Dasgupta, S., \& Glen, J. (1995). Return Behavior in Emerging Stock Markets. The World Bank Economic Review, Vol 9, 131-151.

Elton, E. J. (1999). Expected Return, Realized Return, and Asset Pricing Tests. The Journal of Finance, 1199-1220.

Fayyad, A., \& Daly, K. (2010). The Volatility of Market Returns: A Comparative Study of Emerging versus Mature Markets. International Journal of Business and Management, 24-36.

Glosten, L. R., Jagannathan, R., \& Runkle, D. E. (1993). On the Relation between the Expected Value and the Volatility of the Nominal Excess Return on Stocks. The journal of Finance, 1779-1801.

Jaleel, F. M., \& Samarakoon, L. P. (2009). Stock market liberalization and return volatility: Evidence from the emerging market of Sri Lanka. Journal of Multinational Financial Management, 409-423.

Jegajeevan, S. (2010). Return Volatility and Asymmetric News Effect in Sri Lankan Stock Market. Economic Research Department Central Bank of Sri Lanka Staff Studies - Volume 40 Numbers 1 \& 2, 37-57.

Kim, C. J., Morley, J. C., \& Nelson, C. R. (2004). Positive Relationship between Stock Market Volatility and the Equity Premium? Journal of Money, Credit and Banking, Vol. 36, 339-360.

Kumara, U., Upananda, W. A., \& Rajib, M. S. (2014). Impact of Ethnic War on Dynamic Properties of Stock Return in Colombo Stock Exchange of Sri Lanka. International Conference on Management and Economics (pp. 218-227). Faculty of Management and Finance, University of Ruhuna, Sri Lanka.

Theodossiou, P. (1998). Financial Data and the Skewed Generalized T Distribution . Management Science/Vol 44, 1650-1661. 